\title{
Pollution Abatement Equipment and International Migration
}

\author{
Kenji Kondoh $^{\mathrm{a}^{*}}$
}

${ }^{a}$ Chukyo University, Japan

\begin{abstract}
By introducing a pollution abatement equipment industry into the Copeland and Taylor (1999) model, we find that the real wage rate will be higher in a developed country with a superior pollution abatement technology. On the other hand, the effects of environmental tax policies on the real wage rate would not clear. Migration has positive effects on the wage rate, the stock of the environmental tax and welfare of the worker in at least one country. Finally we show the possibility that both countries gain from international migration.
\end{abstract}

JEL Classifications: F22, J61, Q56

Keywords: international migration, pollution abatement equipment, economic welfare, environmental tax

\section{Introduction}

The importance of the environmental industry, which supplies environmental equipment and services, is steadily increasing given the drive to reduce pollution caused by smokestack industries and to preserve or improve the natural environment. Correspondingly, the global market of the environmental industry is also growing.

Several theoretical studies deal with environmental topics in an international trade model. With regard to the environmental industry, Merrifield (1988) analyzes the effects of equipment standards on trade and capital mobility. Copeland (1991) studies the trade of waste disposal services. Chua (2003) examines the effects of an emission tax on the trade pattern in a three-sector model, in which one sector is the non-tradable pollution abatement service sector. Sugiyama (2003) also studies the effects of environmental

\footnotetext{
* Corresponding author: School of Economics, Chukyo University. Address: 101-2 Yagotohonmachi Showaku Nagoya, 4668666, Japan. Email: kkondo@mecl.chukyo-u.ac.jp. I am grateful to Professor Ngo Van Long (McGill University), Nicola Coniglio (University of Bari), Masayuki Okawa (Ritsumeikan University), an anonymous referee, attendants of 2009 APJAE Symposium (City University of Hong Kong), 51st Annual Meeting of Kansai Branch of the JSIE (Kurume University), and seminars at Chukyo University and Nagasaki University for their constructive comments on a previous version of this study. This work is supported by Grant-in-Aid for Scientific Research 19530255.Any remaining errors are my own.
} 
policies in a two-sector model, in which one sector is the production sector of pollution abatement equipment. Abe and Sugiyama (2008) analyze the structure of comparative advantage determined by the international differences in environmental policies in a model with the pollution abatement equipment, and examine the effects of an environmental policy in an open economy.

There are several researches on the possibilities and effects of international migration in a two-country model considering the economic value of the natural environment. Tawada (2007) introduces the natural environment into the Harris and Todaro (1970) model, investigates the effect of an improvement in pollution abatement technology, and concludes that in the case where urban area is capital intensive, the improvement in pollution abatement technology induces an increase in urban unemployment and a deterioration of the natural environment and national welfare. Kondoh (2006) analyzes the welfare effects of international migration in the presence of trans-boundary pollution by using a simplified version of the Copeland and Taylor (1999) model, in which the developed country's pollution abatement technology is superior to that of the developing country. In the absence of trade, workers migrate from the developing country to the developed country. The developing home country surely gains, but whether the host country gains or not depends on parameters, the abatement technology gap, and the magnitude of the coefficient of trans-boundary pollution. Kondoh (2007) extends Kondoh (2006) by introducing two types of workers: unskilled workers, who contribute only to production in the smokestack manufacturing industry, and skilled workers, who can contribute not only to manufacturing production but also the reduction of pollution. However, note that none of these studies considers environmental abatement equipment or the service sector. Thus, both domestic and trans-boundary pollution will be reduced only by the decrease in the production of manufacturing good through international migration.

The purpose of this study is to investigate the wage gap between a developed domestic country and a developing foreign country, in the presence of a pollution abatement equipment sector. We develop a three-good model: a smokestack manufacturing final good, an environmentally sensitive agricultural final good, and a pollution abatement equipment, which is supplied to the manufacturing industry by the public sector. We find that the real wage rate will be higher in the developed country with a higher productivity in the production of pollution abatement equipment or with superior pollution abatement technology. On the other hand, the effects of environmental taxes on the real wage rate are ambiguous. In at least one of the two countries, migration will cause positive effects on the wage rate, stock of environment, and economic welfare of the representative worker. Moreover, under a certain simple condition, we show that both countries gain from international migration.

The paper is organized as follows. In Section 2, we set up the model and the effects on real wage caused by different abatement technologies or environmental policies in autarky are studied in Section 3. The effects of international migration on the wage rate, environmental capital stock, and economic welfare of each worker are analyzed in Section 4. Finally, Section 5 offers the concluding remarks. 


\section{The Model}

We assume that the world comprises two countries $H$ (home) and $F$ (foreign) with three industries; the smokestack manufacturing industry, which generates pollution; the environmentally sensitive agricultural industry, which suffers from the pollution; and the pollution abatement equipment industry, which is managed by the public sector. We assume that this equipment is just like a filter, which helps to purify polluted air or water. This equipment improves the pollution abatement technology of the manufacturing industry. The two primary factors of production are labor and environmental capital; the latter is the specific factor in the production of the agricultural good.

The production functions of the manufacturing, agricultural and pollution abatement equipment industries in country $H$ are

$$
\begin{aligned}
& M=L_{M}, \\
& A=\sqrt{E} L_{A}, \\
& D=\beta L_{D},
\end{aligned}
$$

where $E$ is the stock of environmental capital; $M$ and $L_{M}$ are, respectively, the output and labor input in the manufacturing industry; $A$ and $L_{A}$ are those of the agricultural industry, $D$ and $L_{D}$ are those of the pollution abatement equipment industry; and $\beta$ is the parameter that reflects the productivity of pollution abatement equipment.

Production activity in the manufacturing industry causes pollution, while with pollution abatement equipments, the pollution abatement technology of the manufacturing industry could be improved. We assume that the emission of pollutants, denoted by $Z$, is proportional to the manufacturing output:

$$
\mathrm{Z}=(\lambda-\mu D) L_{M}=\left(\lambda-\gamma L_{D}\right) L_{M}
$$

Here, $\lambda$ is the pollution abatement technology without any equipment, $\mu$ is the efficiency of an equipment to improve the technology, and $\gamma=\mu \beta$. We assume that pollution abatement technology improves proportionally with the number of equipments.

We assume that the stock of environmental capital decreases with the amount of emission, $Z$. Therefore, the net stock of environmental capital is

$$
E=\bar{E}-Z
$$

where $\bar{E}$ is the natural stock level of environmental capital before damages.

Regarding industry structure, we assume perfect competition with free entry both in the manufacturing and agricultural industries. Let $\pi_{M}$ and $\pi_{A}$ be the total profits of the manufacturing and agricultural industries, expressed as follows:

$$
\pi_{M}=p_{M} M-w L_{M}-t M
$$




$$
\pi_{A}=A-w L_{A},
$$

where the agricultural good is the numeraire; $p_{M}$ and $w$ are, respectively, the price of manufactured good and the wage rate; and $t$ is the specific rate of emission tax. The government supplies pollution abatement equipment to the manufacturing industry free of charge. Thus there is no cost to introduce the equipment. Then, under the assumption that both goods are produced, profit maximization conditions in the manufacturing and agricultural industries yield

$$
\begin{gathered}
\frac{\partial \pi_{M}}{\partial L_{M}}=p_{M}-w-t=0, \\
\frac{\partial \pi_{A}}{\partial L_{A}}=\sqrt{E}-w=0 .
\end{gathered}
$$

The full employment condition of country $H$ is

$$
L_{M}+L_{A}+L_{D}=L
$$

where $L$ is the labor endowment of country $H$.

The pollution abatement equipment industry is managed by the government. The budget constraint of the government is

$$
w L_{D}=t M,
$$

where the LHS of (9) is the labor cost in the pollution abatement equipment industry, while RHS is the tax revenue.

On the demand side, we specify the following social utility function:

$$
U=\left(D_{M}\right)^{\alpha}\left(D_{A}\right)^{1-\alpha}, 0<\alpha<1
$$

where $D_{M}$ and $D_{A}$ are, respectively, aggregate consumption levels of the manufactured and agricultural good. Because of the zero profit of each firm and the government budget constraint, the GDP of country $H$ is equal to labor income, $w L$. Therefore the demand for each good is obtained by solving utility maximization problem, subject to the following budget constraint:

$$
D_{A}+p_{M} D_{M}=w L
$$

Thus, we have

$$
\begin{aligned}
& p_{M} D_{M}=\alpha w L, \\
& D_{A}=(1-\alpha) w L .
\end{aligned}
$$




\section{Wage Difference in Autarkic Equilibrium}

In autarky, the demand of the manufacturing and agricultural goods is equal to the domestic output. Thus, we have

$$
\begin{aligned}
& D_{M}=M, \\
& D_{A}=A .
\end{aligned}
$$

From (5), (7), (12b), and (13b) we have

$$
L_{A}=(1-\alpha) L
$$

and making use of (8) and (1c) we obtain

$$
M-\alpha L+L_{D}=0
$$

On the other hand, from (6), (12a), and (13a) we have

$$
\alpha w L-M(w+t)=0 .
$$

Finally, from (2), (3), and (7) we have

$$
\bar{E}-\left(\lambda-\gamma L_{D}\right) M=w^{2} .
$$

Now we have three equations (15), (16), and (17), which determine three endogenous variables, $w, M$, and $D$, given the exogenous variables $\bar{E}, \alpha, \gamma, L, t$, and $\lambda^{1}$.

We now turn to the economy of country $F$. Variables relating to this country are marked with asterisk. Since we focus on the international difference in the effects of pollution abatement equipment on the level of abatement technology, the productivity of the pollution abatement equipment industry or the emission tax rate imposed by the government, we assume that country $F$ is identical to country $H$ except for one of the exogenous variables $\mu, \beta$ or $t$. Given $\gamma=\beta \mu$, it can be simplified that one of these conditions, $\gamma>\gamma^{*}$ or $t>t^{*}$ is satisfied. In other words, we assume $\mathrm{L}=\mathrm{L}^{*}, \alpha=\alpha^{*}, \bar{E}=\bar{E}^{*}$ and $\lambda=\lambda^{*}$ in deriving all our results.

Totally differentiating (15), (16), and (17) yields:

$$
\left[\begin{array}{ccc}
0 & 1 & 1 \\
\alpha L-M & -(w+t) & 0 \\
2 w & \lambda-\gamma L_{D} & -M \gamma
\end{array}\right]\left[\begin{array}{l}
d w \\
d M \\
d L_{D}
\end{array}\right]=\left[\begin{array}{c}
0 \\
0 \\
M L_{D}
\end{array}\right] d \gamma-\left[\begin{array}{c}
\alpha \\
\alpha w \\
0
\end{array}\right] d L+\left[\begin{array}{c}
0 \\
M \\
0
\end{array}\right] d t
$$

\footnotetext{
${ }^{1}$ It might be necessary to remark that from (15) and (16), we easily can derive (9). In usual case, the government intends to determine tax rate, $t$ to maximize social utility, $U$. But in our analysis, because of strong resistance by the manufacturing industry, we assume that the tax rate is lower than optimal level and exogenously given. Moreover to satisfy (17), we implicitly assume that $\lambda-\gamma L_{D}>0$.
} 
The determinant of the matrix is,

$$
\Delta=(\alpha L-M)\left(\lambda-\gamma L_{D}+M \gamma\right)+2 w(w+t)>0,
$$

from (2) and (15).

3.1 The international difference in the effects of pollution abatement equipment on the level of abatement technology or the international difference in the productivity of the pollution abatement equipment industry

Let us first consider the case where $\mu>\mu^{*}$, which implies that the effect of an increase in the number of pollution abatement equipment on the level of abatement technology is higher in country $H$ than that in country $F$. This assumption is justified if we assume that country $H$ is developed and the quality of the pollution abatement equipment is higher, that is, the filter used to reduce the emission of polluted air or water is of a superior quality. In this case, we also assume that country $F$ is identical to country $H$ except on this point. Therefore, we assume $\beta=\beta^{*}$ and $t=t^{*}$.

Let us consider the case where $\beta>\beta^{*}$, which implies that the productivity of the pollution abatement equipment industry is higher in country $H$ than that in country $F$. This assumption is justified if we assume that the technology of country $H$ is more advanced. Even though there is no difference in the quality of both labor and produced good and labor input is just the same in each country, the output of country $H$ is larger in quantities. We also assume that country $F$ is identical to country $H$ except on this point. Therefore we assume $\mu=\mu^{*}$ and $t=t^{*}$.

Given $\gamma=\beta \mu$, these two cases reduce to the case where $\gamma>\gamma^{*}$ and $t=t^{*}$.

From (18), simple calculations yield

$$
\frac{d w}{d \gamma}=\frac{1}{\Delta} M L_{D}(w+t)>0
$$

which implies $w>w^{*}$. From (6), as $d p_{M}=d w$ under constant tax rate, $t$, we can assert that real income of a worker is higher in country $H$ than in country $F$. Therefore, if international migration is permitted, workers tend to migrate from country $F$ to country $H$.

\subsection{The international difference in the emission tax rate}

Finally let us consider the case that $t>t^{*}$, which implies that the emission tax rate imposed by country $H$ 's government is higher than that by country $F$ 's government. This assumption is reasonable because country $H$ is more sensitive to preserve the environmental capital stock than the developing country $F$. In this case, we also assume that country $F$ is identical to country $H$ except on this point. Therefore, we assume $\beta=\beta^{*}$ and $\mu=\mu^{*}$.

From (18), simple calculations yield

$$
\frac{d w}{d t}=\frac{1}{\Delta} M\left(\gamma M+\lambda-\gamma L_{D}\right)>0,
$$


which implies $w>w^{*}$ in this case. But different from the former two cases, from (6), we have $d p_{M} / d t=d w / d t+1$, which implies $d p_{M} / d t>d w / d t>0$. Therefore, in this case we can conclude $p_{M} / p_{M}{ }^{*}>w / w^{*}>1$ or $w^{*} / p_{M}{ }^{*}>w / p_{M}$. Now the real income of country $H$ is not always higher than that of country $F$. In case $\alpha$ is sufficiently large (small), which means that the consumers' preference is biased to the manufactured (agricultural) good, country $F(H)$ will be the host country for the international immigration.

It is interesting to stress that a too high emission tax rate might reduce real wages, i.e. the government policy might be inefficient if taxes imposed on the production of the polluting goods, $M$, in order to correct a negative externality which affects another good, $A$, when the latter is not so preferred by the consumers.

Now we can offer the following proposition:

\section{Proposition 1}

(1) The international difference in the effects of pollution abatement equipment on the level of abatement technology or the productivity of the pollution abatement equipment industry would cause international migration from the developing country to the developed country.

(2) The international difference in the emission tax rate also cause international migration but the direction depends on the parameter of the preference of consumption.

Additionally, from (18), simple calculations yield

$$
\frac{d\left(\gamma L_{D}\right)}{d \gamma}=L_{D}+\gamma \frac{d L_{D}}{d \gamma}=\frac{1}{\Delta}(\alpha L-M) M \gamma+L_{D}>0,
$$

Therefore, we have $\gamma L_{D}>\gamma^{*} L_{D}{ }^{*}$ in the case of $\beta>\beta^{*}$ or $\mu>\mu^{*}$, which implies that pollution abatement equipment is more effective in country $H$.

\section{International Migration and Welfare}

From Section 3, we can conclude that country $H$, the technology of which is more advanced and suitable for producing high-quality pollution abatement equipment, will be the host country for immigration, if it is permitted. Moreover, if each worker strongly prefers to consume agricultural goods, country $H$ with higher environmental tax rate will also be the host country. Now let us investigate the effects of immigration on the wage rate, production of both manufactured and agricultural goods, environmental capital stock, and welfare.

\subsection{The effects on wage rate}

From (18), applying (9), simple calculations yield

$$
\frac{d w}{d L}=-\frac{\alpha w}{\Delta}\left(\lambda-2 \gamma L_{D}\right)
$$


which implies $d w / d L>(<) 0$ in the case where $\lambda<(>) 2 \gamma L_{D}$. Therefore, applying (22), we have three cases.

The first case is that pollution abatement equipment is sufficiently effective and can reduce more than half of the original emission of pollution by the manufacturing industry in each country. In this case both $\lambda<2 \gamma L_{D}$ and $\lambda^{*}<2 \gamma^{*} L_{D}{ }^{*}$ are satisfied and international immigration will raise the wage rate in country $H$. On the other hand, the wage rate in country $F$ will decrease by the outflow of workers. Thus, international migration expands the wage gap between the two countries and the incentive of migration will continue. But even though these two inequalities can hold initially, they cannot continue to hold for a long time. Eventually, as workers migrate to country $H$, there are very few workers left in country $F$, so $2 \gamma^{*} L_{D}{ }^{*}$ will eventually be smaller than $\lambda^{*}$. Let us call this Case 1 .

The second case is that the pollution abatement equipment is not sufficiently effective and it can reduce less than half of the original emission of pollution by the manufacturing industry in each country. In this case both $\lambda<2 \gamma L_{D}$ and $\lambda^{*}<2 \gamma^{*} L_{D}{ }^{*}$ are satisfied and international migration will reduce the wage rate of country $H$, raise the wage rate of country $F$, and therefore reduce the gap between the two countries. In this case, after several episodes of migration, the steady state, in which no wage gap and no motivation for migration anymore, may emerge. Let us call this Case 2.

Recalling that we have $\gamma L_{D}>\gamma^{*} L_{D}{ }^{*}$ in the case of $\beta>\beta^{*}$ or $\mu>\mu^{*}$, there is possibly a third case which satisfies $2 \gamma L_{D}>\lambda=\lambda^{*}>2 \gamma^{*} L_{D}{ }^{*}$. In this case, from (23), we can conclude that migration from country $F$ to country $H$ will raise the wage rates of both countries. Let us call this Case 3.

\subsection{The effects on production and environmental capital}

From (18), simple calculations yield

$$
\begin{aligned}
& \frac{d M}{d L}=\frac{1}{\Delta} \alpha\left[2 w^{2}+\gamma M(\alpha L-M)\right]>0, \\
& \frac{d L_{D}}{d L}=\frac{1}{\Delta} \alpha\left[(\alpha L-M)\left(\lambda-\gamma L_{D}\right)+2 w t\right]>0 .
\end{aligned}
$$

The abovementioned results show that because of international migration, the production of both the manufacturing and pollution abatement equipment industries in country $H(F)$ will increase (decrease).

Regarding the effect on the environmental capital stock, we have the following relationship from (7),

$$
\operatorname{sgn} \frac{d w}{d L}=\operatorname{sgn} \frac{d E}{d L},
$$


which implies that the environmental capital stock of country $H$ will increase (decrease) after migration in Cases 1 and 3 (Case 2), and that of country $F$ will increase (decrease) in Cases 2 and 3 (Case 1), respectively ${ }^{2}$.

\subsection{The effect on welfare}

Next let us consider the effect on welfare. In this model, as there is no profit by the competitive firms in the manufacturing industry, national welfare will be equal to the economic welfare of the workers. The expenditure function of a representative worker is defined as

$$
e\left(p_{M}, u\right)=w
$$

where $u$ denotes the utility level of a representative worker in country $H$. Totally differentiating (27) yields

$$
\frac{\partial e}{\partial p_{M}} d p_{M}+\frac{\partial e}{\partial u} d u=d w
$$

From Shephard's Lemma, we have $\frac{\partial e}{\partial p_{M}}=m$, where $m$ denotes per capita consumption of manufactured good in country $H$. Given $m=\frac{M}{L}=\frac{L_{M}}{L}<1$ and $d p_{M}=d w$ under constant tax rate, (28) yields

$$
\frac{\partial e}{\partial u} d u=(1-m) d w
$$

and therefore we obtain

$$
\operatorname{sgn} \frac{d u}{d L}=\operatorname{sgn} \frac{d w}{d L}
$$

As a result, in case of $\lambda<(>) 2 \gamma L_{D}$, we can conclude $d u / d L>(<) 0$, respectively, which implies that welfare in country $H$ will increase (decrease) after migration in Cases 1 and 3 (Case 2), and that of country $F$ will increase (decrease) in Cases 2 and 3 (Case 1), respectively. Now we establish the following proposition:

\section{Proposition 2}

(1) If pollution abatement equipment is sufficiently effective and can reduce more than half of the original emission of pollution by the manufacturing industry in each country,

\footnotetext{
${ }^{2}$ We could obtain the same results from the following equation: $\frac{d E}{d L}=-\left(\lambda-\gamma L_{D}\right) \frac{d M}{d L}+\gamma M \frac{d L_{D}}{d L}$, by applying (2) and (3).
} 
international migration will raise (reduce) the wage rate, environmental capital stock, and welfare of the host (source) country.

(2) If pollution abatement equipment is not sufficiently effective and can reduce less than half of the original emission of pollution by the manufacturing industry in each country, international migration will reduce (raise) the wage rate, environmental capital stock, and welfare of the host (source) country.

(3) If pollution abatement equipment is sufficiently effective (not sufficiently effective) and it can reduce more (less) than half of the original emission of pollution by the manufacturing industry in the developed (developing) country, international migration will cause global gain, that is, raise the wage rate, environmental capital stock, and welfare of both countries.

The implications of the above proposition are as follows. In the case of a quite effective pollution abatement equipment industry, while immigration expands the production of smokestack manufacturing industry, it also expands the production of pollution abatement equipment. The latter effect dominates and causes positive externalities on the production of agricultural good by increasing the stock level of environmental capital. The increased productivity of the agricultural sector will raise the wage rate of workers in terms of agricultural good. Because of the above effects, the representative consumer can gain from international immigration. On the other hand, in the case of a quite ineffective pollution abatement equipment industry, we can obtain the opposite results by similar scenarios.

Kondoh (2006) studies the case without the pollution abatement equipment industry and his Theorem 1; we can easily conclude that with the difference in pollution abatement technology and without trans-boundary pollution, the developed country will surely lose from international immigration. On the other hand, the developing country will necessarily gain. However, by introducing the public-managed industry of pollution abatement equipment, the inflow of labor will expand the production of the equipment industry, which will contribute to the welfare of the developed country. Therefore, unlike Kondoh (2006), we have a special possibility that both the countries can gain from international migration.

\section{Concluding Remarks}

We introduced the environmental industry, which supplies pollution abatement equipment, into the Copeland and Taylor (1999) model. We found that the real wage rate will be higher in the developed country with a higher productivity in the production of pollution abatement equipment or with a superior pollution abatement technology. On the other hand, the effects on the real wage rate caused by environmental tax policies are ambiguous. After the permission for international migration, at least in one of the two countries, migration will cause positive effects on the wage rate, stock of environment, and economic welfare of the representative worker. Moreover, under a certain simple condition, we showed that both the countries gain from international migration. 
In this model, we compared the case under international migration with the case of autarky. But instead of international migration, international trade might occur. Because in autarky, under the condition of $\beta>\beta^{*}$ or $\mu>\mu^{*}$, the relative price of the manufactured good is higher in the developed country, namely, $p_{M}>p_{M}{ }^{*}$. Therefore, because of the comparative advantage, if it is permitted, country $H$ will start to export the agricultural good and import the manufactured good. This trade pattern is reflected in Kondoh (2006). A future research topic is considering the possibility and effects of international migration under free international trade. In this case, we might take into account the possible cases where one of the two countries does not produce all three goods.

In modifying Copeland and Taylor's (1999) model to allow for migration, we simplified some aspects of that model following Kondoh (2006), for example, the dynamic aspect relating to the natural recovery of environmental capital. A worthwhile extension of our research would be to analyze international migration taking into account the dynamic specification of the original Copeland and Taylor model.

\section{References}

Abe, K., and Y. Sugiyama, 2008, "Pollution Abatement Equipments, Environmental Policies, and International Trade", Unpublished Manuscript.

Chua, S., 2003, "Does Tighter Environmental Policy Lead to a Comparative Advantage in Less Polluting Goods?" Oxford Economic Papers 55, 25-35.

Copeland, B.R., 1991, "International Trade in Waste Products in the Presence of Illegal Disposal", Journal of Environmental Economics and Management 20, 143-162.

Copeland, B.R., and S. Taylor, 1999, "Trade, Spatial Separation and the Environment", Journal of International Economics 47, 137-168.

Harris, J.R. and M. Todaro, 1970, "Migration, Unemployment and Development: A Two Sector Analysis," American Economic Review 60, 126-142.

Kondoh, K., 2006, “Transboundary Pollution and International Migration”, Review of International Economics 14, 248-260.

Kondoh, K., 2007, “Trans-boundary Pollution and Brain Drain Migration”, Review of Development Economics 11, 333-345.

Merrifield, H.D., 1988, “The Impact of Selected Abatement Strategies on Transnational

Pollution, the Terms of Trade, and Factor Rewards: A General Equilibrium

Approach", Journal of Environmental Economics and Management 15, 259-284.

Sugiyama, Y., 2003, "Emission Tax, Subsidy to Input of the Pollution Abatement Equipment and International Trade (in Japanese)", The International Economy 8, 57-76.

Tawada, M., 2007, "On the Harris-Todaro Paradoxes in an Environmental Issue (in Japanese)", The Journal of Economics in Kwansei Gakuin University 60-3, 1-14. 
